\title{
Guest editorial comment
}

\author{
by Sammy Y. N. Chan and M. Anson, Concrete Technology Group, Hong Kong Polytechnic
}

\author{
High-strength concrete: the Hong Kong experience
}

In the past, high-strength concrete (HSC) has mainly been employed in specialist areas such as prestressed concrete, precast concrete products and nuclear containment. In the past decade, however, in situ HSC has increasingly been adopted for the construction of tall commercial buildings. Against this background, the development and use of superplasticizers, structural engineering design and reinforced concrete have seen significant advances. In China, concrete with grades of over 50 has been used for skyscrapers in several major cities. In Hong Kong, concrete up to grade 65 has been used for tall buildings and for structures subject to aggressive industrial environments.

It can be demonstrated that the replacement of normalgrade concrete (say grade 30 ) by HSC igrade 60 and above) can greatly reduce the consumption of reinforcing steel and concrete materials. For example, the steel content of a multistorey reinforced concrete column was $6 \%$ at base level. When the grade 30 concrete was replaced by grade 60 , the saving in reinforcement was $240 \mathrm{~kg} / \mathrm{m}^{3}$. Alternatively, the cross-sectional area of a multistorey column could be reduced by $48 \%$ if a grade 30 concrete with $3 \%$ steel were replaced by a grade 60 concrete using the same quality of steel. In the case of a major city such as Hong Kong, where office space costs over US $\$ 12000$ per $\mathrm{m}^{2}$, the extra revenue generated by the additional floor space could be very large indeed. Because of these considerations the further development and promotion of HSC is well justified technically and economically.

There is no absolute definition of HSC. In different countries, in different times, or even at different locations in the same country, the term has been defined differently. In the $1950 \mathrm{~s}$, grade 35 concrete was regarded as highstrength; in the 1960 s grade 40 to 50 . Since the 1970 s, grade 60 has generally been accepted as HSC. In the USA in the $1950 \mathrm{~s}$, concretes of up to grade 35 were used on major tall buildings. In the $1970 \mathrm{~s}$, grade 60 concrete was used on tall buildings such as Water Tower Place in Chicago. In the late 1980 s, Number 2 Union Square in Seattle utilized in situ concrete of $129 \mathrm{~N} / \mathrm{mm}^{2}$ for its columns.

Attempts have been made to standardize the term 'HSC'. ASTM defines concrete of grade 41 and above as high-strength; FIP/CEB defines concrete with $60 \mathrm{~N} / \mathrm{mm}^{2}$ cylinder compressive strength as highstrength and concrete with $100 \mathrm{~N} / \mathrm{mm}^{2}$ cylinder compressive strength as very-high-strength.

In the $1960 \mathrm{~s}$, the introduction of superplasticizers propelled the development of HSC into a new era. Even for a very low water-cement ratio $(w / c)$, high workability can be achieved with the inclusion of a superplasticizer. This enabled the attainment of high strengths while maintaining workability for in situ construction. In recent years, there have been further developments of HSC. Apart from higher strength cements, superplasticizers and $w / c s$, there are superfine fillers and pozzolanic strengthening agents, which make production of veryhigh-strength concrete $\left(>100 \mathrm{~N} / \mathrm{mm}^{2}\right)$ possible. For example, in the USA, $20 \%$ silica fume replacement and a w/c of 0.22 together with a superplasticizer were used to make a concrete with a crushing strength of $124 \mathrm{~N} / \mathrm{mm}^{2}$ and a flexural strength of $14 \mathrm{~N} / \mathrm{mm}^{2}$ while attaining a slump of 100-200 $\mathrm{mm}$. In Japan, there have been attempts to make cement particles of spherical shape, further reducing the water demand of concrete. Attemps have also been made to develop self-compacting concrete and self-curing concrete, which can be regarded as new types of high-performance concretes. In China, the use of low-cost strengthening agents such as oil shale ash and zeolitic minerals has been developed to substitute for the expensive silica fume, as a result of which there is no cost penalty in the production of HSC. To overcome the more rapid slump loss in superplasticized $\mathrm{HSC}$ and to facilitate pumping of this type of concrete, a fluidifier carrier has been developed in China. In Italy, a carboxylic acrylic 
ester admixture has been developed for similar purposes. Both of these admixtures can maintain the workability of concrete mixes for over $2 \mathrm{~h}$.

From the above, it can be seen that HSC has progressed from being based solely on low $w / c$ ratio and vigorous vibration, to give low water-cementitious $(w / c+p)$ ratio, superplasticized and high-flowing HSC. Recently, HSC has been further developed to include spherical cement particles, superfine fillers, pozzolanic strengthening agents, superplasticizers, fluidifier carrier and carboxylic acrylic ester that can greatly prolong the consistency of concrete.

Hong Kong, being one of the major commercial centres in the world, is home to some of the greatest buildings and civil engineering structures. Due to its inherent cost advantages, availability and versatility, concrete is one of the most commonly used contruction materials in Hong Kong. In fact, the tallest concrete building in the world, the $378 \mathrm{~m}$ high Central Plaza which utilized HSC of grade 60 , was completed recently. The ever-increasing demands for taller buildings, longer-span bridges/beams and higher space/structure efficiency both in Hong Kong and in the economically thriving China make it vital that their construction industry is kept up to date and ahead in all aspects of concrete technology to improve their competitiveness in the world market.

With this in mind, a new research centre has recently been established by Hong Kong Polytechnic with the principal objective of studying high-performance concrete. Two aspects, HSC and high-flowing concrete (HFC) have been selected for the initial phase of the work. HSC has the benefits of increased mechanical strength, improved durability, high modulus and low cost per unit of floor area, while HFC, which has high workability but without the drawback of segregation, could potentially accelerate the construction programme and process significantly. Both types of concrete are particularly beneficial to highrise development and fast-track construction in Hong Kong. Apart from study of a wide range of mechanical, physical and durability properties of HSC and HFC, a research programme has been set up to study their performance under the influence of elevated temperatures and fire in order to ensure that these new materials will not constitute a hazard during fires.

Durability research efforts are concentrating on the study of concrete structures exposed to aggressive environments in Hong Kong and China. Test methods will also be developed to assist the local construction industry in assessing the durability potential of new concrete structures. 